\title{
Gender Climate in Indian Oncology and Other Sectors
}

\author{
Sujata Saunik ${ }^{1}$ \\ ${ }^{1}$ IAS, Takemi Fellow, Takemi Program in International Health, Harvard \\ T.H Chan School of Public Health, United States of America \\ Ind J Med Paediatr Oncol 2022;43:8-9.
}

Address for correspondence Sujata Saunik, Additional Chief Secretary (ACS), Services Department, Government of Maharashtra, 16, Suniti, General Bhosale Marg, Nariman Point, Mumbai - 400021, India (e-mail: ssaunik@gmail.com).
Cancer causes one of the highest numbers of cases related to non-communicable diseases (NCDs). According to GLOBOCAN 2020, India reported 1.32 million cancer cases in $2020 .^{1}$ It has been observed that cancer is affecting more women than men in India. However, the opposite trend is observed in other countries. As per the National Institute of Cancer Prevention and Research, one woman dies of cervical cancer every eight minutes in India and one of every two women newly diagnosed with breast cancer dies. ${ }^{2}$ These contrasting results are being examined, and the reasons are being identified. Such gender disparity is observed not only in oncology but also across sectors. This paper highlights gender disparity issues in oncology and other sectors using findings of insurance-based health scheme, surveys among oncology professionals, and certain personal experiences to substantiate the argument. ${ }^{3}$

A comprehensive analysis of medical oncology cases treatment under the insurance-based health scheme of Maharashtra named Mahatma Jyoti Rao Phule Jan Arogya Yojana (MJPJAY) from 2012 to 2020 reveals the following.

Almost $30.5 \%$ of the beneficiaries are treated for cancerrelated general surgery, followed by cardio-thoracic (16.9\%) and nephrology (13.8\%). It was found that the share of male beneficiaries (58.2\%) is more than that of the female (41.8\%) who sought treatment. This is particularly problematic given that the incidence of some form of cancer was found to be disproportionately higher among women (43.8\%) than men (20.9\%).

The third key finding is that $34.7 \%$ of patients migrated from their place of residence in the state to avail treatment for cancer and other NCDs. Most beneficiaries opted for private hospitals closer to their home, if available or migrated to another location, especially for the treatment of cancer. It was found that a large number of cancer patients took treatment at Tata Memorial Hospital in Mumbai, a large public trust hospital, as it is affordable and is also a state-ofthe-art tertiary care center in the state. Cardiac problems, (21.9\%) followed by renal and pediatric problems (12.2 percent), were the top causes for mortality. Deaths due to cancer are almost $5.8 \%$ of the total casualties.

Notably, it was found that the share of cancer patients is increasing over time and the share of cardiac patients is decreasing. This could be due to late detection and start of treatment by patients and better treatment outcomes for other NCDs like cardiac, nephrology, etc.

Over the past decade, cancer has been identified as one of the most critical public health and economic challenges. ${ }^{4}$ The burden of diagnosis and treatment has a disproportionate impact on women. As per the Lancet Commission on women and cancer, of the 311,365 women who died of cervical cancer in 2018, nearly nine in ten lived in low-income or middleincome countries. ${ }^{5}$ Perhaps, this is the reason why the Lancet Commission has organized a panel discussion focusing on the state of global cancer and women's health in 2021.

While gender-based inequality is not restricted to the oncology community, the implications are more adverse for the fraternity given that women form the bulk of the caseload in India.

The Global Gender Gap Report 2021 puts India's gender gap at $62.5 \%$ on account of poor participation of women in politics, technology, and leadership roles, decrease in women's labor force participation rate, poor health care, lagging female-to-male literacy ratio, income inequality, etc. ${ }^{6}$

The coronavirus disease 2019 pandemic has further accelerated digitization and automation leading to labor market disruption. The gender gap is more likely in sectors that require high technical skills, for instance, artificial intelligence, cloud computing, data analytics, etc.
DOI https://doi.org/ $10.1055 / \mathrm{s}-0042-1742652$. ISSN 0971-5851.
(C) 2022. Indian Society of Medical and Paediatric Oncology. All rights reserved.

This is an open access article published by Thieme under the terms of the Creative Commons Attribution-NonDerivative-NonCommercial-License, permitting copying and reproduction so long as the original work is given appropriate credit. Contents may not be used for commercial purposes, or adapted, remixed, transformed or built upon. (https://creativecommons.org/ licenses/by-nc-nd/4.0/)

Thieme Medical and Scientific Publishers Pvt. Ltd., A-12, 2nd Floor, Sector 2, Noida-201301 UP, India 
The United Nations report of 2020 highlights that almost 83\% of legal frameworks that promote, enforce, and regulate gender equality are in place in India. ${ }^{7}$ However, early marriages and child birth, high school and college education dropout rates, physical and sexual harassment at workplace, and less access of women to assets including land means closing the gender gap in India still requires more policy framing and enabling environment in the future. As per an article published by Boston Consulting Group (BCG) in 2021, it is found that climate change is likely to have a disproportionate impact on women. ${ }^{8}$ Their livelihood may take a severe hit compared to men due to global warming. However, incorporating a gender perspective on climate-related action plans and ensuring equity in economic opportunities may address this growing concern.

Every industry in India employs more men than women. A study done by LinkedIn using their own database of professionals on their site has some very interesting findings. It found that the gender gap among Indian professionals is worse than the global average in every sector. In the Indian formal sector, the gender gap is at least, $85 \%$ comprising of men in sectors like transportation, construction, and manufacturing. In hi-tech, the gap is almost $72 \% .^{9}$ Only two industries in India have equal representation of men and women, primary and secondary education at $46 \%$ and human resources at $51 \%{ }^{9}$ Globally, four of the seventeen industry groups, legal, education, medical, and health care have more women representation than men. But in India even in these sectors there are more men than women. ${ }^{9}$ The reason could be that overall gender norms prevent women from seeking work and discourage employers from hiring them. The transportation and manufacturing sectors have the worst gender balance in India. Most leading companies in this sector, including Tata Motors and Maruti Suzuki, have more than 85\% male workforce. ${ }^{9}$ Other companies that employ more men than women are Amazon India, Google India, Tata Consultancy Services, and companies in the IT, aviation, and pharmaceuticals sectors. Perhaps the representation of women in technical institutes may help improve the scenario as only $10 \%$ females are at the Indian Institutes of Technology as against $45 \%$ in the Massachusetts Institute of Technology. ${ }^{9}$ As per the LinkedIn Opportunity Index 2021, 85\% women in India have missed out on a raise, promotion because of their gender. ${ }^{10}$

There could be several factors inhibiting the increase of female participation in industry and more efforts need to be made for increasing these numbers. Gender-neutral employment policies shall definitely encourage more balance. Promotions and growth within the industry should be based on merit and performance.

Recently concluded in the UN Climate Change Conference, women are underrepresented in most country delegations. At the UN Climate Change Conference (COP26), women constituted more than $50 \%$ of country delegations in only 35 of the 195 nations. Half of the countries had less than 33\% female delegations. The speaking time of party delegates at meetings showed men, in general, spoke longer than their female counterparts.

Women face several constraints at the workplace in terms of equal opportunity to handle sensitive and tough assignments and need to work doubly hard to prove their worth at every stage. Often, they juggle the numerous roles in their professional and personal lives, and there is never a time when "work is done"! Perception is a big part of the way personnel look at women employees. Requests for time off, leave, medical emergencies, leaving the workplace early on occasion and not volunteering for extra work are often held against women workers, which is at cross purposes of the different roles they play. Investing time in higher learning and professional training can often be to the advantage of women aspiring for top positions in their organizations. The most important aspect of professional growth for women is to support and lift each other up. By investing in such a network, they can reap a whole career's worth of benefits that would elude many who try and make the lone journey.

In order to address gender disparity concerns, we must use the principles of the theory of behavioral science for health outcomes to understand the barriers and strategies for increased participation. This includes providing information and options available for health care for various diseases and treatment. The approach has to be sensitive to respective cultures as well.

There is also a strong need to implement dedicated outreach programs using audiovisual mediums to communicate about preventive health care, diet, habits for a healthy lifestyle, and benefits of health-seeking behavior. Given appropriate "nudges" can create awareness and trigger responses, which can result in addressing gender disparity in health.

Conflict of Interest

None declared.

\section{References}

1 Citing an online article: Global Cancer Data: GLOBOCAN 2020. Accessed December 2021 at: https://gco.iarc.fr/today/data/ factsheets/populations/356-india-fact-sheets.pdf

2 Citing an online article: cancer statistics - India against cancer. Accessed December 2021 at: http://cancerindia.org.in/cancer-statistics/

3 Bajpai J, Mailankody S, Nair R, et al. Gender climate in Indian oncology: national survey report. ESMO Open 2020;5(02):e000671

4 Citing an online article: World Health Organization: cancer factsheet. Accessed December 2021 at: https://www.who. int/news-room/fact-sheets/detail/cancer

5 Stelzle D, Tanaka L, Lee K, et al. Estimates of the global burden of cervical cancer associated with HIV. Lancet Glob Health 2021;9 (02):e161-e169

6 Citing an online article: Global Gender Gap Report 2021. Accessed December 2021 at: https://www.weforum.org/reports/globalgender-gap-report-2021

7 Citing an online article: UN Women- Annual Report. Accessed December 2021 at: https://www.weforum.org/reports/ab6795a1960c-42b2-b3d5-587eccda6023

8 Citing an online article: Boston Consulting Group 2021-Why climate action needs a gender focus. Accessed December 2021 at: https://www.bcg.com/publications/2021/climate-actionimpact-on-gender-equality

9 Citing an online article: gender gap in Indian formal sector. Accessed December 2021 at: https://www.hindustantimes.com/ india-news/gender-gap-in-indian-formal-sector-worse-than-globalaverage-linkedin-data-shows/story-yOtfsFNazeMZbOnjGL9a1I.html

10 Citing an online article: LinkedIn Opportunity Index 2021. Accessed December 2021 at: https://news.linkedin.com/content/dam/me/ news/en-us/images/Opportunity_Index_Whitepaper_Final_1604. pdf 